\title{
Wheat gluten protein and its impacts on wheat processing quality
}

\author{
Wujun MA (ه), Zitong YU, Maoyun SHE, Yun ZHAO, Shahidul ISLAM \\ State Agriculture Biotechnology Centre, School of Veterinary and Life Sciences, Murdoch University, Perth WA 6150, Australia
}

\begin{abstract}
Before the advent of the wheat genomic era, a wide range of studies were conducted to understand the chemistry and functions of the wheat storage proteins, which are the major determinants of wheat flour the suitability of wheat flour for various end products, such as bread, noodles and cakes. Wheat grain protein is divided into gluten and non-gluten fractions and the wheat processing quality mainly depends on the gluten fractions. Gluten provides the unique extensibility and elasticity of dough that are essential for various wheat end products. Disulfide bonds are formed between cysteine residues, which is the chemical bases for the physical properties of dough. Based on the SDS-extractability, grain protein is divided into SDS-unextractable polymeric protein (UPP) and SDS-extractable polymeric protein. The percentage of UPP is positively related to the formation of disulfide bonds in the dough matrix. In the wheat genomic era, new glutenins with long repetitive central domains that contain a high number of consensus hexapeptide and nonapeptide motifs as well as high content of cysteine and glutamine residues should be targeted.
\end{abstract}

Keywords wheat gluten, consensus motifs, disulfide bonds, SDS-unextractable polymeric protein, glutenins, gliadins, processing quality, storage protein

\section{Wheat grain protein classification}

Bread wheat grain proteins are generally divided into gluten and non-gluten proteins (Fig. 1). Both gluten and non-gluten proteins are located mainly in the embryo, aleurone layer and endosperm of the grain, with the endosperm containing most of the gluten. The gluten protein fraction accounts for about $85 \%$ of total grain protein. Based on the solubility in aqueous alcohols and acid solution, glutens are divided into polymeric glutenins

Received March 7, 2019; accepted April 24, 2019

Correspondence: w.ma@murdoch.edu.au and monomeric gliadins in a proportion of $40 \%$ and $60 \%$, respectively ${ }^{[1]}$. According to the molecular weight distribution, glutenins are classified into high molecular weight (70000-90000 Da) glutenin subunits and low molecular weight (20000-45000 Da) glutenin subunits (HMW-GS and LMW-GS), which account for $40 \%$ and $60 \%$ of glutenin composition, respectively. Based on the order of mobility on electrophoresis at low $\mathrm{pH}$, monomeric gliadins are classified into $\alpha / \beta-, \gamma$ - and $\omega$-gliadins, which represent approximately 55\%, 30\% and $15 \%$ in gliadin fractions, respectively ${ }^{[2,3]}$. The non-gluten protein includes albumins (water-soluble protein) and globulins (saltsoluble protein). These are mainly biochemical functional proteins such as chaperones and enzymes, which regulate the accumulation and synthesis of storage proteins, and grain growth ${ }^{[4,5]}$.

\section{Wheat gluten protein variations}

Glutens are the major constituents of bread wheat grain storage proteins and constitute $85 \%$ of the total. They are mainly responsible for the processing quality of wheat dough and were among the first proteins isolated and studied by human beings. Their biological function is to provide carbon, nitrogen and energy sources for seed germination and seedling growth. Mutations or silencing of such genes are not lethal for the plant, so the evolutionary selection pressure on these genes is much lower than for functional genes ${ }^{[6]}$. As a result, these genes can accumulate more mutations, making them ideal model molecules for studying a range of biological fundamental processes ${ }^{[7-10]}$. It is worth noting that past work has been primarily focused on the applied aspects of using these proteins to increase wheat end product quality. Their value in theoretical research has been largely ignored. So far, only Zhang et al. ${ }^{[8]}$ has reported a biological function other than the storage function for gluten, an antifungal function of a newly identified special gluten protein, namely aveninlike protein, which is quite similar to the gliadins in 


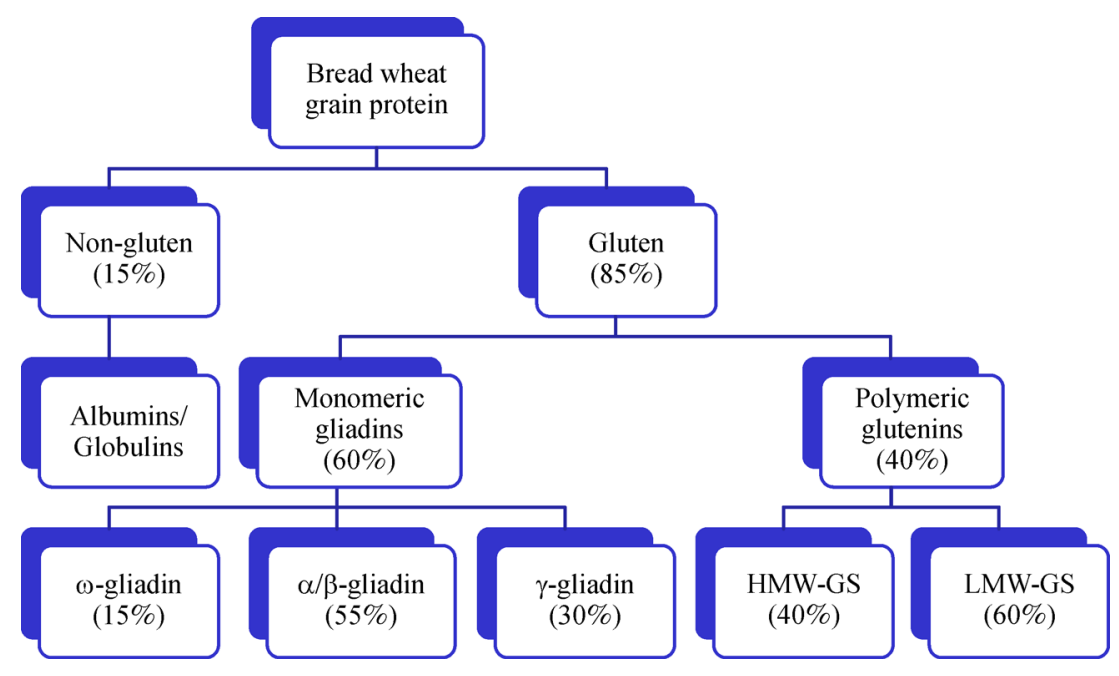

Fig. 1 Classification of wheat grain proteins

structure. Until now, extensive studies have provided substantial information about the relationship between gluten structures and properties in relation to end product quality. The first systematic study was conducted by Osborne $^{[2]}$, who developed a classification for cereal-seed proteins based on their sequential extraction and differential solubility. Four different groups were classified, including (1) albumins, soluble in water and dilute buffers, (2) globulins, not soluble in water but soluble in saline solutions, (3) gliadins, soluble in $70 \%$ to $90 \%$ ethanol, and (4) glutenins, soluble in dilute acid or alkali. The two distinct groups of the gluten polymer that were classified reflected their solubility in $70 \%$ ethanol, namely glutenins and gliadins ${ }^{[11,12]}$. The gliadins are single polypeptide chains and the glutenins are multichained structures of polypeptides that are held together by disulfide bonds. The high molecular weight of these polymeric structures is responsible for their partial insolubility and for their contribution to food-product quality. Therefore, the classification of these proteins into monomeric and polymeric forms is a good indicator of their functional properties $^{[13]}$.

In most dicotyledonous, and some monocotyledon seeds, the globulin types predominate in the seed. However, in the Triticeae (wheat, barley and rye) the major portion of seed proteins are not globulins, but classes of protein characterized by regular repetitive domains with unique and fundamental functional features ${ }^{[14,15]}$. These proteins are glutenins in wheat and variation in them either quantitatively or qualitatively has major effects on end product quality ${ }^{[16-18]}$. It is worth noting that although some water-soluble proteins are also found present in the dough gluten matrix and have some impacts on wheat processing quality ${ }^{[19]}$, the glutenins and gliadins are still the dominant proteins in defining wheat processing quality. The predictive power of glutenin subunit proteins for flour processing properties has been demonstrated for dough rheological properties, such as dough extensibility and elasticity ${ }^{[18,20,21]}$. Strong dough will form a cohesive mass that has resistance to extension and can retain stability during mixing. Such dough is able to hold the gas produced during fermentation within evenly distributed discrete cells in the dough structure. This results in a loaf crumb in which the gas cells are of regular size and even distribution. Such a crumb structure appears light in color, fine and silky in texture, both highly desirable quality attributes. Soft gluten will allow the gas cells to expand excessively during fermentation, causing their walls to collapse and the cells to coalesce together, resulting in the bread having an open texture with a coarse wall structure $^{[22]}$.

The investigation of glutenin proteins in relation to dough properties have indicated two key variables: (1) the nature of the protein allele ${ }^{[16,23]}$ and (2) the level at which the respective allele is expressed ${ }^{[24,25]}$. The control of the level of expression of seed storage protein has been well studied $^{[26-28]}$. Studies of the regulatory mechanism of gene expression performed by Wanous et al. ${ }^{[29]}$ revealed that 15 chromosome arms had significant effects on Glu-B1-1, 19 on Glu-B1-2, 20 on Glu-D1-1 and 25 on Glu-D1-2. In addition, the orthologous loci (both $\mathrm{x}$-type and $\mathrm{y}$-type HMW-GS) are influenced by the same regulatory systems and there is less correlation between paralogous genes, although considerable conservation was observed at this level. However, there are chromosome sequences not coding for any structural genes that affect the expression of seed storage protein encoding genes in wheat. Chromosome $1 \mathrm{D}$ and $2 \mathrm{~A}$ sequences can affect the expression of gliadin genes located on chromosome $6 \mathrm{~A}$ and $6 \mathrm{D}$, respectively ${ }^{[30,31]}$. The DNA structures of most of the glutenin genes have been determined ${ }^{[24,32-35]}$. The prolamins forming the polymer are mainly HMW-GS and LMW-GS, while the monomeric (polymer non-participating) prolamins are called $\alpha / \beta-, \gamma-$, and $\omega$-gliadins. It is 
worth noting that the $\alpha$ - and $\omega$-gliadins have been confirmed to be the cause of human celiac disease and wheat intolerance, while the glutenins are classified as nontoxic, weakly toxic or not as toxic as gliadins ${ }^{[36]}$. The variation in celiac disease epitopes in the $\alpha$-gliadin gene family of hexaploid wheat has been extensively studied ${ }^{[37-39]}$.

HMW-GS proteins are a major determinant of gluten elasticity through promoting the formation of larger glutenin polymers and thus are key factors for breadmaking $^{[40]}$. They are encoded by the Glu-1 loci Glu-A1, Glu-B1 and Glu-D1 that are located on the long arms of chromosome 1A, 1B and 1D, respectively. Each locus includes two genes linked together encoding two different types of HMW glutenin subunits, $x$-type and y-type subunits ${ }^{[41-43]}$. The $x$-type subunits generally have a higher molecular weight than that of y-type subunits ${ }^{[4]}$. Payne and Lawrence ${ }^{[13]}$ summarized the number of alleles at Glu-1 loci, three allelic forms for Glu-1A, 11 alleles for $G l u-1 B$, and six alleles for Glu-1D. More alleles have been identified since as reported by researchers ${ }^{[45-47]}$. Most alleles in modern hexaploid wheat cultivars emerged before hexaploid wheat was formed, only By18 subunit has been confirmed to have emerged after hexaploid wheat formation ${ }^{[48]}$. Many gluten alleles did not enter into the hexaploid wheat during evolution or have been discarded through modern breeding ${ }^{[7,35]}$. Although six genes exist for HMW glutenin subunits, due to gene silencing, most hexaploid wheat cultivars possess three to five HMW glutenin subunits ${ }^{[33]}$. All hexaploid wheat genotypes contain at least Bx, Dx and Dy subunit in their endosperm, while most cultivars also contain a By subunit and an Ax subunit. The gene encoding Ay subunit is usually silent ${ }^{[33,49]}$. By introducing an active Ay gene into Australian common wheat cultivars, Roy et al. ${ }^{[50]}$ found significant positive effects of the Ay subunit on processing quality. Other allelic effects associated with HMW glutenins have been well documented. The one most reported and used is Dx $5+10^{[16,51,52]}$. Increased dough strength can also be achieved through an increase in expression of the $\mathrm{Bx} 7$ subunit, which results in approximately $130 \mathrm{BU}$ (Brabender units) over the average of the other alleles at that locus ${ }^{[20,24]}$. It has been observed that the overexpression of Glu-1Bx7 improves dough strength by stabilizing the gluten network, whereas Glu-1Bx17 and Glu-1Dx2 do not ${ }^{[33]}$. Compared to the normal Bx7 gene, the gene conferring $\mathrm{Bx} 7$ overexpression has an $18 \mathrm{bp}$ insertion in the central repetitive domain, a $43 \mathrm{bp}$ indel of the $5^{\prime}$-region and the left and right junctions of the LTR retrotransposon borders and the duplicated segment, and has been used to developed PCR markers as well as high throughput KASP markers for differentiating these two genotypes $^{[54,55]}$. Other allelic variants also have differential effects on dough quality, e.g., Glu-B1 subunits $17+18$ are associated with strong dough while subunits $20 x+20 y$ are associated with weak dough ${ }^{[56]}$. Statistical analysis of large numbers of durum wheat genotypes confirmed the strong correlation of $\gamma$-gliadin 45 with good processing quality and $\gamma$-gliadin 42 with poor processing quality. Moreover, loaf volume during the baking process has a negative relationship with acetic acid-soluble glutenin and a positive relationship with acetic acid-insoluble glute$\operatorname{nin}^{[11]}$. For extensibility, Cornish et al. ${ }^{[56]}$ suggested this was a more complex trait involving other parameters such as LMW-GS and gliadin compositions. However, gliadins appear to be less important in determining bread quality, and the addition of gliadins or the overexpression of certain gliadins can reduce dough strength ${ }^{[57]}$. Wieser ${ }^{[58]}$ found that hydrated gliadins have little elasticity but contribute to the viscosity and extensibility of the dough system, whereas, hydrated glutenins are responsible for both cohesive and elastic properties.

\section{Gluten protein structure and component variations and their impacts on dough quality}

Typically, the structure of gluten protein is determined by three general domains, one central domain rich in a repetitive structure constituting a $\beta$-reverse turn and two terminal $\alpha$-helix domains ${ }^{[59]}$. A long repetitive domain of the glutenin is considered to have a positive influence on wheat flour quality due to the formation of more $\beta$-reverse turn structures ${ }^{[40,60]}$. The proportion of the consensus hexapeptides and nonapeptides in the repetitive domain also affect dough quality. Masci et al. ${ }^{[61]}$ reported that a large and regular repeated sequence domain increases the viscosity and elasticity of doughs through intermolecular interactions. Wang et al. ${ }^{[25]}$ reported that the hexapeptide motif is more important than the nonapeptide motif. In terms of secondary and high order structure, gluten protein can aggregate to form a complex protein network through disulfide bonds during the dough mixing process. In general, most y-type subunits contain seven cysteines (five in the $\mathrm{N}$-terminal domain and one in each of the repetitive and $\mathrm{C}$-terminal domains), the $\mathrm{x}$-type subunits possess four cysteines (three in the N-terminal domain and one in the C-terminal domain $)^{[62,63]}$. However, different subunits possess different numbers of cysteines. For example, the subunit 1Dx5 has five cysteines (three in the N-terminal domain and one in each of the repetitive and C-terminal domains) and 1Dx2 only has four cysteines, meaning that 1Dx5 possesses positive allelic effects over $1 \mathrm{Dx} 2$ on dough strength ${ }^{[64,65]}$. Also, $\mathrm{Ax} 2 * \mathrm{~B}$ is a novel variant of the Ax2* subunit, which contains an extra cysteine residue located in the middle of its repetitive domain, exerts a positive effect on the gluten properties ${ }^{[66]}$. In contrast, Bx14 and Bx20 subunits have reduced numbers of cysteine residues in their N-terminal domains and usually have negative effects on dough strength ${ }^{[64]}$. Apart from the disulfide bonds, Gilbert et al. ${ }^{[67]}$ found that hydrogen bonds formed through glutamine can stabilize the polymeric structure of glutenin. Studies have revealed that a 
high content of glutamine of both HMW and LMW glutenins have positive effects on dough quality ${ }^{[6]}$. Extra covalent bonds and intermolecular crosslinks of tyrosines in the form of isodityrosine or dityrosine were found to form during the dough mixing and baking process among gluten proteins of wheat at the site of repeats of pairs of tyrosine residues throughout the central repetitive domains ${ }^{[59]}$. Oxidizing agents, such as ascorbic acid, azodicarbonamide, and potassium bromate, can facilitate the formation of dityrosine or isotyrosine during the baking processing. Therefore, tyrosine is also important for the maintenance of secondary, tertiary or quaternary structure of gluten despite being present at a relative low proportion $(3 \%-5 \%)$. Cysteine, glutathione, butylated hydroxytoluene and other reductive agents on the other hand are capable of not only cleaving disulfide bonds but also inhibiting tyrosine bond formation via their free radical scavenging activities ${ }^{[62,69]}$. However, Peña et al. ${ }^{[70]}$ indicated that crosslinks between tyrosine residues appear to be few and of little importance in the structure of the gluten network compared to the disulfide bonds formed between cysteine residues. Less than $0.1 \%$ of the tyrosyl residues participate in the crosslinks by forming dityrosine, isodityrosine, trityrosine and pulcherosine, and is determined by the number of tyrosyl residues in the central repetitive domain of glutenins. Of those, dityrosine residues are only of minor importance in the structure of wheat gluten ${ }^{[71]}$. The large gluten polymers consisting of HMW-GSs, LMW-GSs and other relevant proteins determine the end-use value of wheat flour by affecting dough mixing and gluten formation. However, there are no definitive structural differences among different glutenin subunits which show a close relationship with their ability to form gluten.

Gluten component variations also have a significant impact on dough physical and physicochemical properties. The classic interaction network of gluten involves the backbone formed by HMW-GSs joined by LMW-GSs and gliadins through disulfide bonds and noncovalent bonds, respectively ${ }^{[72]}$. Among them, the x-type HMW-GSs confer wheat gluten strength and the ratio of tenacity/ extensibility (P/L), and LMW-GSs, together with gliadins, function as solvent which modifies the rheological properties of dough either by interfering with the polymerization of HMW-GS, or by altering relative amounts of different glutenin subunit types ${ }^{[70]}$. In detail, W was strongly relevant to the quantity of x-type HMW-GS. This has been confirmed by Halford et al. ${ }^{[73]}$ who showed that wheat carrying the active alleles of Glu-Al (containing $\mathrm{Ax} 1$ or $\mathrm{Ax} 2 *$ subunit) can produce higher strength gluten and this was further supported by the positive effects associated with an active y-type HMW glutenin alleles encoded by Glu-A1 (containing Ay subunit). Besides, a positive correlation existed between rheological parameters $\mathrm{W}$ and $\mathrm{P} / \mathrm{L}$ and the total quantity of $\mathrm{x}$-type HMWGSs, while a negative correlation was found between P/L and gliadins/HMW ratio and LMW/HMW ratio ${ }^{[53]}$. As Ahmad et al. ${ }^{[3]}$ proposed, correlations exist between gliadins and certain rheological variables. Therefore, there must be a balance between different types of proteins for the formation of the gluten network and the HMW-GSs contributing to the formation of gluten network, and especially x-type glutenin subunits have an important role in the polymerization, whereas gliadins interfere with the polymerization. Furthermore, Uthayakumaran et al. ${ }^{[74]}$ found a relationship between extensibility and gliadin quantity and a negative correlation between LMW-GSs quantity and $\mathrm{P} / \mathrm{L}$ results in an extensible property. These results indicate that the quantities of different gluten protein fractions are more important than the types of alleles available ${ }^{[53]}$. A newly characterized storage protein class, avenin-like proteins, that is similar to gliadin in structure with high number of cysteine residues was found to have positive effect on dough strength ${ }^{[75]}$.

Different compositions of wheat storage proteins confer different dough physical properties that are required by different end products ${ }^{[76,77]}$. For example, pasta making requires dough with high gluten strength, but dough for biscuit making needs low gluten strength with high extensibility. Breadmaking needs moderate gluten strength and high extensibility dough, while noodle making needs dough with a balance of gluten strength and extensibility in order to protect dough from tearing during the manufacturing process. In addition, confectionery products such as cake and cookies need flour with weak gluten ${ }^{[78]}$. Therefore, it is the balance between elasticity and extensibility that determines the suitability and quality of wheat flour for different end products.

\section{Core factors affecting dough storage protein composition and viscoelastic properties}

As mentioned above, gluten functionality is due to the essential role of disulfide bonds, which are formed between sulfhydryl groups of cysteine residue ${ }^{[79,80]}$. The cysteine residue are important in the formation of a gluten network and maintaining gluten functionality. Dough elasticity is primarily associated with the polymeric glutenins, which form both intramolecular and intermolecular disulfide bonds, whereas, dough extensibility mainly results from the monomeric gliadins, which form only intramolecular disulfide bonds ${ }^{[79,81]}$. It has been reported that intramolecular disulfide bonds form more rapidly than intermolecular disulfide bonds ${ }^{[12]}$. According to the distribution of cysteine residues, gluten subunits can be divided into S-poor ( $\omega$-gliadin and HMW-GS) and S-rich $(\alpha / \beta-$, $\gamma$-gliadins and LMW-GS) subunits. The $\alpha / \beta-, \gamma$-gliadins and LMW-GS contain two or four times more cysteine residues than HMW-GS; $\omega$-gliadin contains no cysteine or methionine residues ${ }^{[79]}$. 
Differences in soil sulfur availability may change the proportion of S-poor ( $\omega$-gliadin and HMW-GS) and S-rich $(\alpha / \beta-, \gamma$-gliadins and LMW-GS) subunits and thus alter the grain storage protein composition, which may eventually lead to variation in the grain quality ${ }^{[82-85]}$. Less sulfur availability in grain leads to an increase of S-poor subunit quantity including $\omega$-gliadin and HMW-GS, and there is a slight reduction in the amount of gliadins and LMW-GS. Therefore, a decreased sulfur content is positively related to an increased ratio of HMW-GS to LMW-GS. These compositional changes could lead to an increased elasticity and a decreased extensibility in gluten functionality ${ }^{[86,87]}$. In contrast, high sulfur availability in grain relates to an increased proportion of S-rich subunits, which results in an increased proportion of LMW-GS, $\alpha / \beta / \gamma$-gliadin and a decreased proportion of HMW-GS and $\omega$-gliadin, and an altered molecular weight distribution ${ }^{[83,85,87-89]}$. Ultimately, the effect of high sulfur content will decrease elasticity and simultaneously increase extensibility ${ }^{[00,91]}$.

Apart from the effects on gluten protein composition, another possible impact of sulfur on dough quality is due to the tripeptide glutathione. Sulfur uptake is generally in the form of sulfate, which is then converted into cysteine that forms disulfide bonds important in maintaining gluten functionality through various steps involving activation and reduction ${ }^{[92,93]}$. Furthermore, cysteine is metaboliized into glutathione in free reduced and free oxidized (GSSG) forms, as well as in the form of protein-glutathione mixed disulfides ${ }^{[94]}$. First, the balance between GSSG and GSH is maintained in favor of oxidants such as ascorbic acid and potassium bromate, acting as electron sources ${ }^{[95-97]}$. Free GSH could react with intermolecular disulfide bonds, which results in breakdown of disulfide bonds and damage to the the structure of polymeric glutenins that ultimately weakens the elasticity of dough. However, free GSSG can react with $\mathrm{SH}$ groups of gluten proteins, which results in release of GSH and damages the linkages of disulfide bonds, ultimately weakening the dough quality ${ }^{[98,99]}$. Therefore, an excessively high sulfur supply to wheat may increase the formation of glutathione, which is negatively related to dough quality and tends to decrease wheat processing quality.

Based on the extractability of grain protein fractions in the SDS extraction buffer, grain protein compositions can be divided into SDS-unextractable polymeric protein (UPP; glutenin macropolymer) and SDS-extractable polymeric protein (EPP). The concentration of UPP $(\sim 20$ $40 \mathrm{mg} \cdot \mathrm{g}^{-1}$ ) in total grain protein is crucial in determining gluten strength and breadmaking quality ${ }^{[58]}$. UPP is positively related to the formation of the gluten network which is formed by interlinking disulfide bonds and responsible for dough functionality. The percentage of UPP is a reliable reference for dough quality. The growth environment has less effect on UPP accumulation in the process of grain development. In contrast, EPP has been reported to be influenced by environmental factors ${ }^{[100,101]}$.
Although the accumulation of polymeric proteins starts as early as $7 \mathrm{~d}$ post-anthesis and lasts during the entire period of grain development, the accumulation of UPP fraction only begins at the later stage of grain development (from 30 to $45 \mathrm{~d}$ post-anthesis). Yu et al. ${ }^{[102]}$ found that UPP formation involves peptidyl-prolyl cis-trans isomerase (PPIase) SUMOylation with the assistance of small ubiquitin-related modifier 1 and that high nitrogen availability facilitates this connection. Additionally, luminal binding protein 2 in the endoplasmic reticulum has a similar function to PPIase in the aggregation of protein. The formation of UPP is closely related to the process of moisture loss during grain-filling ${ }^{[103]}$. It has also been reported that the significant changes in size distribution of polymers only occurs during the later stage of seed development, which corresponds with the period of a sharp increase in glutenin subunit amount during cell division and enlargement. Glutenin subunits have a large number of free $\mathrm{SH}$ groups and are oxidized during water loss, which is also when UPP is formed ${ }^{[104,105]}$.

\section{Conclusions}

Extensive studies have been conducted to understand the fundamental mechanisms underlying the effect of gluten on wheat end product quality. The HMW glutenin proportion has the greatest impact on dough quality. The current progress in wheat genome research has made it easy to search for novel gluten genes for wheat quality improvement. Based on the findings of gluten research, in the wheat genomic era, new HMW glutenins identified from wheat relatives and historical landraces with long central repetitive domains that contain high number of consensus hexapeptide and nonapeptide motifs as well as high content of cysteine and glutamine residues should be investigated for their potential to improve wheat end-use quality.

Compliance with ethics guidelines Wujun Ma, Zitong Yu, Maoyun She, Yun Zhao, and Shahidul Islam declare that they have no conflicts of interest or financial conflicts to disclose.

This article is a review and does not contain any studies with human or animal subjects performed by any of the authors.

\section{References}

1. Sapirstein H D, Fu B X. Intercultivar variation in the quantity of monomeric proteins, soluble and insoluble glutenin, and residue protein in wheat flour and relationships to breadmaking quality. Cereal Chemistry, 1998, 75(4): 500-507

2. Osborne T B. The proteins of the wheat kernel. Washington DC: Carnegie Institution of Washington, 1907

3. Ahmad M, Griffin W, Sutton K. Genetic evaluation of gliadin and glutenin subunits and their correlations to rheological properties in 
bread wheat. Journal of Genetics \& Breeding, 2000, 54(2): 143147

4. Bean S, Tilley M. Separation of water-soluble proteins from cereals by high-performance capillary electrophoresis (HPCE). Cereal Chemistry, 2003, 80(5): 505-510

5. Majoul T, Bancel E, Triboï E, Ben Hamida J, Branlard G. Proteomic analysis of the effect of heat stress on hexaploid wheat grain: characterization of heat-responsive proteins from nonprolamins fraction. Proteomics, 2004, 4(2): 505-513

6. Liu S, Gao X, Xia G. Characterizing HMW-GS alleles of decaploid Agropyron elongatum in relation to evolution and wheat breeding. Theoretical and Applied Genetics, 2008, 116(3): 325-334

7. Zhang Y, Cao X, Juhasz A, Islam S, Qi P, She M, Zhu Z, Hu X, Yu Z, Wylie S, Dowla M, Chen X, Yang R, Xia X, Zhang J, Zhao Y, Shi N, Dell B, He Z, Ma W. Wheat avenin-like protein and its significant fusarium head blight resistant functions. bioRxiv, 2018: 406694

8. Zhang Y, Hu X, Islam S, She M, Peng Y, Yu Z, Wylie S, Juhasz A, Dowla M, Yang R, Zhang J, Wang X, Dell B, Chen X, Nevo E, Sun $\mathrm{D}$, Ma W. New insights into the evolution of wheat avenin-like proteins in wild emmer wheat (Triticum dicoccoides). Proceedings of the National Academy of Sciences of the United States of America, 2018, 115(52): 13312-13317

9. Li X, Ma W, Gao L, Zhang Y, Wang A, Ji K, Wang K, Appels R, Yan Y. A novel chimeric low-molecular-weight glutenin subunit gene from the wild relatives of wheat Aegilops kotschyi and Ae. juvenalis: evolution at the Glu-3 loci. Genetics, 2008, 180(1): 93101

10. Zhang Y, Li X, Wang A, An X, Zhang Q, Pei Y, Gao L, Ma W, Appels R, Yan Y. Novel X-type high-molecular-weight glutenin genes from Aegilops tauschii and their implications on the wheat origin and evolution mechanism of Glu-D1-1 proteins. Genetics, 2008, 178(1): 23-33

11. Wrigley C W. Giant proteins with flour power. Nature, 1996, 381 (6585): 738-739

12. Shewry P R, Casey R. Seed proteins. In: Seed proteins. Shewry P R and Casey R, eds. Dordrecht: Springer Netherlands, 1999, 1-10

13. Payne P I, Lawrence G J. Catalogue of alleles for the complex gene loci, Glu-A1, Glu-B1, and Glu-D1 which code for high-molecularweight subunits of glutenin in hexaploid wheat. Cereal Research Communications, 1983, 11(1): 29-35

14. MacRitchie F, DuCros D L, Wrigley C W. Flour polypeptides related to wheat quality. In: Advances in cereal science and technology (Pomeranz, Y., ed), St Paul, Minnesota. USA: American Association of Cereal Chemists Inc., 1990, 79-145

15. Shewry P R, Halford N G. Cereal seed storage proteins: structures, properties and role in grain utilization. Journal of Experimental Botany, 2002, 53(370): 947-958

16. Ma W, Appels R, Bekes F, Larroque O, Morell M K, Gale K R. Genetic characterisation of dough rheological properties in a wheat doubled haploid population: additive genetic effects and epistatic interactions. Theoretical and Applied Genetics, 2005, 111(3): 410 422

17. Mann G, Diffey S, Cullis B, Azanza F, Martin D, Kelly A, McIntyre L, Schmidt A, Ma W, Nath Z, Kutty I, Leyne P E, Rampling L, Quail K J, Morell M K. Genetic control of wheat quality: interactions between chromosomal regions determining protein content and composition, dough rheology, and sponge and dough baking properties. Theoretical and Applied Genetics, 2009, 118(8): $1519-1537$

18. Jiang P, Xue J, Duan L, Gu Y, Mu J, Han S, Chen L, Li Y, Ma W, Yan Y, Li X. Effects of high-molecular-weight glutenin subunit combination in common wheat on the quality of crumb structure. Journal of the Science of Food and Agriculture, 2019, 99(4): 1501-1508

19. Gao L, Wang A, Li X, Dong K, Wang K, Appels R, Ma W, Yan Y. Wheat quality related differential expressions of albumins and globulins revealed by two-dimensional difference gel electrophoresis (2-D DIGE). Journal of Proteomics, 2009, 73(2): 279-296

20. Eagles H A, Eastwood R F, Hollamby G J, Martin E M, Cornish G B. Revision of the estimates of glutenin gene effects at the Glu-BI locus from southern australian wheat breeding programs. Australian Journal of Agricultural Research, 2004, 55(10): 1093-1096

21. Eagles H A, Hollamby G J, Gororo N N, Eastwood R F. Estimation and utilisation of glutenin gene effects from the analysis of unbalanced data from wheat breeding programs. Australian Journal of Agricultural Research, 2002, 53(4): 367-377

22. Simmonds D H. Inherent quality factors in wheat. Wheat and wheat quality in Australia. Melbourne: Austraila Wheat Board, 1989

23. Gras P W, Anderssen R S, Keentok M, Békés F, Appels R. Gluten protein functionality in wheat flour processing: a review. Australian Journal of Agricultural Research, 2001, 52(12): 1311-1323

24. Butow B J, Ma W, Gale K R, Cornish G B, Rampling L, Larroque O, Morell M K, Békés F. Molecular discrimination of Bx7 alleles demonstrates that a highly expressed high-molecular-weight glutenin allele has a major impact on wheat flour dough strength. Theoretical and Applied Genetics, 2003, 107(8): 1524-1532

25. Wang S, Yu Z, Cao M, Shen X, Li N, Li X, Ma W, Weißgerber H, Zeller F, Hsam S, Yan Y. Molecular mechanisms of HMW glutenin subunits from $1 \mathrm{~S}(1)$ genome of Aegilops longissima positively affecting wheat breadmaking quality. PLoS One, 2013, 8(4): e58947

26. Jia M, Guan J, Zhai Z, Geng S, Zhang X, Mao L, Li A. Wheat functional genomics in the era of next generation sequencing: an update. Crop Journal, 2018, 6(1): 7-14

27. Ravel C, Nagy I J, Martre P, Sourdille P, Dardevet M, Balfourier F, Pont C, Giancola S, Praud S, Charmet G. Single nucleotide polymorphism, genetic mapping, and expression of genes coding for the DOF wheat prolamin-box binding factor. Functional \& Integrative Genomics, 2006, 6(4): 310-321

28. She M, Ye X, Yan Y, Howit C, Belgard M, Ma W. Gene networks in the synthesis and deposition of protein polymers during grain development of wheat. Functional \& Integrative Genomics, 2011, 11(1): 23-35

29. Wanous M K, Munkvold J D, Kruse J D, Brachman E E, Klawiter M A, Fuehrer K J. Identification of chromosome arms influencing expression of the HMW glutenins in wheat. Theoretical and Applied Genetics, 2003, 106(2): 213-220

30. Brown J W, Flavell R B. Fractionation of wheat gliadin and 
glutenin subunits by two-dimensional electrophoresis and the role of group 6 and group 2 chromosomes in gliadin synthesis. Theoretical and Applied Genetics, 1981, 59(6): 349-359

31. Bittel D C, Hueros G, Jouve N, Gustafson J P. Changes in expression of seed storage protein genes effected by chromosome 1d of wheat. Genome, 1991, 34(6): 845-848

32. Anderson J V, Morris C F. Purification and analysis of wheat grain polyphenol oxidase (PPO) protein. Cereal Chemistry, 2003, 80(2): 135-143

33. Ma W, Zhang W, Gale K R. Multiplex-PCR typing of high molecular weight glutenin alleles in wheat. Euphytica, 2003, 134 (1): 51-60

34. Zhao X L, Xia X C, He Z H, Gale K R, Lei Z S, Appels R, Ma W. Characterization of three low-molecular-weight Glu-D3 subunit genes in common wheat. Theoretical and Applied Genetics, 2006, 113(7): 1247-1259

35. Zheng W, Peng Y, Ma J, Appels R, Sun D, Ma W. High frequency of abnormal high molecular weight glutenin alleles in Chinese wheat landraces of the Yangtze-river region. Journal of Cereal Science, 2011, 54(3): 401-408

36. Shewry P R, Tatham A S. Improving wheat to remove coeliac epitopes but retain functionality. Journal of Cereal Science, 2016, 67: $12-21$

37. Molberg O, Uhlen A K, Jensen T, Flaete N S, Fleckenstein B, Arentz-Hansen H, Raki M, Lundin K E A, Sollid L M. Mapping of gluten T-cell epitopes in the bread wheat ancestors: implications for celiac disease. Gastroenterology, 2005, 128(2): 393-401

38. Spaenij-Dekking L, Kooy-Winkelaar Y, Koning F. The Ethiopian cereal tef in celiac disease. New England Journal of Medicine, 2005, 353(16): 1748-1749

39. Juhász A, Belova T, Florides C G, Maulis C, Fischer I, Gell G, Birinyi Z, Ong J, Keeble-Gagnère G, Maharajan A, Ma W, Gibson P, Jia J, Lang D, Mayer K F X, Spannagl M, Tye-Din J A, Appels $\mathrm{R}$, Olsen O-A. Genome mapping of seed-borne allergens and immunoresponsive proteins in wheat. Science Advances, 2018, 4 (8): eaar8602

40. Tatham A S, Miflin B J, Shewry P R. The beta-turn conformation in wheat gluten proteins: relationship to gluten elasticity. Cereal Chemistry, 1985, 62: 405-412

41. Payne P I, Corfield K G, Holt L M, Blackman J A. Correlations between the inheritance of certain high-molecular weight subunits of glutenin and bread-making quality in progenies of six crosses of bread wheat. Journal of the Science of Food and Agriculture, 1981, 32(1): 51-60

42. Payne I. Genetics of wheat storage proteins and the effect of allelic variation on bread making quality. Annual Review of Plant Physiology, 1987, 38(1): 141-153

43. Shewry P R, Halford N G, Tatham A S. High molecular weight subunits of wheat glutenin. Journal of Cereal Science, 1992, 15(2): $105-120$

44. Liu L, Wang A, Appels R, Ma J, Xia X, Lan P, He Z, Bekes F, Yan Y, Ma W. A MALDI-TOF based analysis of high molecular weight glutenin subunits for wheat breeding. Journal of Cereal Science, 2009, 50(2): 295-301

45. McIntosh R A, Yamazaki Y, Dudcovsky K, Rogers K M, Morris C, Appels R. Catalogue of gene symbols for wheat. In: Proceedings of the 10th International Wheat Genetics Symposium 2003, Paestum, Italy. 2003, 4: 1-6

46. Liu Z, Yan Z, Wan Y, Liu K, Zheng Y, Wang D. Analysis of HMW glutenin subunits and their coding sequences in two diploid Aegilops species. Theoretical and Applied Genetics, 2003, 106(8): $1368-1378$

47. Sun X, Hu S, Liu X, Qian W, Hao S, Zhang A, Wang D. Characterization of the HMW glutenin subunits from Aegilops searsii and identification of a novel variant HMW glutenin subunit. Theoretical and Applied Genetics, 2006, 113(4): 631-641

48. Liang X, Zhen S, Han C, Wang C, Li X, Ma W, Yan Y. Molecular characterization and marker development for hexaploid wheatspecific HMW glutenin subunit 1By18 gene. Molecular Breeding, 2015, 35(12): 221

49. Yu Z, Peng Y, Islam M S, She M, Lu M, Lafiandra D, Roy N, Juhasz A, Yan G, Ma W. Molecular characterization and phylogenetic analysis of active y-type high molecular weight glutenin subunit genes at Glu-Al locus in wheat. Journal of Cereal Science, 2019, 86: 9-14

50. Roy N, Islam S, Ma J, Lu M, Torok K, Tomoskozi S, Bekes F, Lafiandra D, Appels R, Ma W. Expressed Ay HMW glutenin subunit in Australian wheat cultivars indicates a positive effect on wheat quality. Journal of Cereal Science, 2018, 79: 494-500

51. Lafiandra D, D’Ovidio R, Porceddu E, Margiotta B, Colaprico G. New data supporting high Mr glutenin subunit 5 as the determinant of quality differences among the Pairs $5+10$ vs. $2+12$. Journal of Cereal Science, 1993, 18(2): 197-205

52. Gupta R B, MacRitchie F. Allelic variation at glutenin subunit and gliadin loci, Glu-1, Glu-3 and Gli-1 of common wheats. II. Biochemical basis of the allelic effects on dough properties. Journal of Cereal Science, 1994, 19(1): 19-29

53. Peña E, Bernardo A, Soler C, Jouve N. Relationship between common wheat gluten proteins and dough rheological properties. Euphytica, 2005, 143(1): 169-177

54. Ragupathy R, Naeem H A, Reimer E, Lukow O M, Sapirstein H D, Cloutier S. Evolutionary origin of the segmental duplication encompassing the wheat GLU-B1 locus encoding the overexpressed $\mathrm{Bx} 7\left(\mathrm{Bx} 7^{\mathrm{OE}}\right)$ high molecular weight glutenin subunit. Theoretical and Applied Genetics, 2008, 116(2): 283-296

55. Rasheed A, Wen W, Gao F, Zhai S, Jin H, Liu J, Guo Q, Zhang Y, Dreisigacker S, Xia X, He Z. Development and validation of KASP assays for genes underpinning key economic traits in bread wheat. Theoretical and Applied Genetics, 2016, 129(10): 1843-1860

56. Cornish G B, Skylas D J, Siriamornpun S, Békés F, Larroque O R, Wrigley C W, Wootton M. Grain proteins as markers of genetic traits in wheat. Australian Journal of Agricultural Research, 2001, 52(12): 1161-1171

57. Fido R J, Békés F, Gras P W, Tatham A S. Effects of $\alpha-, \beta-, \gamma$ - and $\omega$-gliadins on the dough mixing properties of wheat flour. Journal of Cereal Science, 1997, 26(3): 271-277

58. Wieser H. Chemistry of gluten proteins. Food Microbiology, 2007, 24(2): 115-119

59. Tilley K A, Benjamin R E, Bagorogoza K E, Okot-Kotber B M, Prakash O, Kwen H. Tyrosine cross-links: molecular basis of gluten structure and function. Journal of Agricultural and Food Chemistry, 2001, 49(5): 2627-2632 
60. Belton P. Mini review: on the elasticity of wheat gluten. Journal of Cereal Science, 1999, 29(2): 103-107

61. Masci S, D'Ovidio R, Lafiandra D, Kasarda D D. Characterization of a low-molecular-weight glutenin subunit gene from bread wheat and the corresponding protein that represents a major subunit of the glutenin polymer. Plant Physiology, 1998, 118(4): 1147-1158

62. Köhler P, Belitz H D, Wieser H. Disulphide bonds in wheat gluten: further cystine peptides from high molecular weight (HMW) and low molecular weight (LMW) subunits of glutenin and from $\gamma$-gliadins. European Food Research and Technology, 1993, 196 (3): 239-247

63. Shewry P R, Tatham A S, Lazzeri P. Biotechnology of wheat quality. Journal of the Science of Food and Agriculture, 1997, 73 (4): 397-406

64. Shewry P R, Gilbert S M, Savage A W, Tatham A S, Wan Y F, Belton P S, Wellner N, D’Ovidio R, Békés F, Halford N G. Sequence and properties of HMW subunit $1 \mathrm{~B} \times 20$ from pasta wheat (Triticum durum) which is associated with poor end use properties. Theoretical and Applied Genetics, 2003, 106(4): 744-750

65. Li W, Wan Y, Liu Z, Liu K, Liu X, Li B, Li Z, Zhang X, Dong Y, Wang D. Molecular characterization of HMW glutenin subunit allele 1Bx14: further insights in to the evolution of Glu-B1-1 alleles in wheat and related species. Theoretical and Applied Genetics, 2004, 109(5): 1093-1104

66. Juhász A, Gardonyi M, Tamas L, Bedo Z. Characterisation of the promoter region of Glu-1Bx7 gene from overexpressing lines of an old Hungarian wheat variety. In: Proceedings of the 10th International Wheat Genetics Symposium 2003, Paestum, Italy. 2003, 3: 1348-1350

67. Gilbert S M, Wellner N, Belton P S, Greenfield J A, Siligardi G, Shewry P R, Tatham A S. Expression and characterisation of a highly repetitive peptide derived from a wheat seed storage protein. Protein Structure and Molecular Enzymology, 2000, 1479(1-2): 135-146

68. Li X, Wang A, Xiao Y, Yan Y, He Z, Appels R, Ma W, Hsam S L $\mathrm{K}$, Zeller $\mathrm{F}$ J. Cloning and characterization of a novel low molecular weight glutenin subunit gene at the Glu-A3 locus from wild emmer wheat (Triticum turgidum 1. Var. Dicoccoides). Euphytica, 2008, 159(1): 181-190

69. Holler T P, Hopkins P B. A qualitative fluorescence-based assay for tyrosyl radical scavenging activity: ovothiol A is an efficient scavenger. Analytical Biochemistry, 1989, 180(2): 326-330

70. Peña E, Bernardo A, Soler C, Jouve N. Do tyrosine crosslinks contribute to the formation of the gluten network in common wheat (Triticum aestivum L.) dough? Journal of Cereal Science, 2006, 44 (2): 144-153

71. Hanft F, Koehler P. Quantitation of dityrosine in wheat flour and dough by liquid chromatography-tandem mass spectrometry. Journal of Agricultural and Food Chemistry, 2005, 53(7): 24182423

72. Don C, Lichtendonk W J, Plijter J J, Hamer R J. Understanding the link between GMP and dough: from glutenin particles in flour towards developed dough. Journal of Cereal Science, 2003, 38(2): $157-165$

73. Halford N G, Field J M, Blair H, Urwin P, Moore K, Robert L, Thompson R, Flavell R B, Tatham A S, Shewry P R. Analysis of
HMW glutenin subunits encoded by chromosome 1A of bread wheat (Triticum aestivum L.) indicates quantitative effects on grain quality. Theoretical and Applied Genetics, 1992, 83(3): 373378

74. Uthayakumaran S, Lukow O M, Jordan M C, Cloutier S. Development of genetically modified wheat to assess its dough functional properties. Molecular Breeding, 2003, 11(4): 249-258

75. Chen X Y, Cao X Y, Zhang Y J, Islam S, Zhang J J, Yang R C, Liu J J, Li G Y, Appels R, Keeble-Gagnere G, Ji W Q, He Z H, Ma W J. Genetic characterization of cysteine-rich type-b avenin-like protein coding genes in common wheat. Scientific Reports, 2016, 6(1): 30692

76. Wall J S. The role of wheat proteins in determining baking quality. Recent Advances in the Biochemistry of Cereals, 1979: 275-311

77. Weegels P L, Hamer R J, Schofield J D. Functional properties of wheat glutenin. Journal of Cereal Science, 1996, 23(1): 1-17

78. Bangur R, Batey I, McKenzie E, MacRitchie F. Dependence of extensograph parameters on wheat protein composition measured by SE-HPLC. Journal of Cereal Science, 1997, 25(3): 237-241

79. Shewry P R, Tatham A S. Disulphide bonds in wheat gluten proteins. Journal of Cereal Science, 1997, 25(3): 207-227

80. Zhao F J, Hawkesford M J, McGrath S P. Sulphur assimilation and effects on yield and quality of wheat. Journal of Cereal Science, 1999, 30(1): 1-17

81. Singh H, MacRitchie F. Application of polymer science to properties of gluten. Journal of Cereal Science, 2001, 33(3): 231-243

82. Moss H J, Randall P J, Wrigley C W. Alteration to grain, flour and dough quality in three wheat types with variation in soil sulfur supply. Journal of Cereal Science, 1983, 1(4): 255-264

83. Wrigley C W, Du Cros D L, Fullington J G, Kasarda D D. Changes in polypeptide composition and grain quality due to sulfur deficiency in wheat. Journal of Cereal Science, 1984, 2(1): 15-24

84. Castle S, Randall P. Effects of sulfur deficiency on the synthesis and accumulation of proteins in the developing wheat seed. Functional Plant Biology, 1987, 14(5): 503-516

85. Fullington J G, Miskelly D M, Wrigley C W, Kasarda D D. Quality-related endosperm proteins in sulfur-deficient and normal wheat grain. Journal of Cereal Science, 1987, 5(3): 233-245

86. MacRitchie F, Gupta R. Functionality-composition relationships of wheat flour as a result of variation in sulfur availability. Australian Journal of Agricultural Research, 1993, 44(8): 1767-1774

87. Zhao F J, Salmon S E, Withers P J A, Monaghan J M, Evans E J, Shewry P R, McGrath S P. Variation in the breadmaking quality and rheological properties of wheat in relation to sulphur nutrition under field conditions. Journal of Cereal Science, 1999, 30(1): 1931

88. Moss H, Wrigley C, MacRichie R, Randall P. Sulfur and nitrogen fertilizer effects on wheat. II. Influence on grain quality. Australian Journal of Agricultural Research, 1981, 32(2): 213-226

89. Wooding A R. Agricultural strategies to reduce dough mixing requirements. Dissertation for the Doctoral Degree. Sydney: University of Sydney, 1997

90. Dupont F M, Altenbach S B. Molecular and biochemical impacts of environmental factors on wheat grain development and protein synthesis. Journal of Cereal Science, 2003, 38(2): 133-146 
91. Field J M, Shewry P R, Miflin B J. Solubilisation and characterisation of wheat gluten proteins: correlations between the amount of aggregated proteins and baking quality. Journal of the Science of Food and Agriculture, 1983, 34(4): 370-377

92. Setya A, Murillo M, Leustek T. Sulfate reduction in higher plants: molecular evidence for a novel 5'-adenylylsulfate reductase. Proceedings of the National Academy of Sciences of the United States of America, 1996, 93(23): 13383-13388

93. Wray J L, Campbell E I, Roberts M A, Gutierrez-Marcos J F. Redefining reductive sulfate assimilation in higher plants: a role for APS reductase, a new member of the thioredoxin superfamily? Chemico-Biological Interactions, 1998, 109(1-3): 153-167

94. Chen X, Schofield J D. Determination of protein-glutathione mixed disulfides in wheat flour. Journal of Agricultural and Food Chemistry, 1995, 43(9): 2362-2368

95. Grosch W. Redox systems in dough. In: Chemistry and physics of baking: Materials, processes, and products: the proceedings of an international symposium organised by the food chemistry group of the royal society of chemistry and the school of agriculture of the university of nottingham, the school of agriculture, sutton bonington, 10th-12th April 1985. Blanshard J M V, Frazier P J, Galliard T, eds. London: Royal Society of Chemistry, 1986

96. Chen X, Schofield J D. Effects of dough mixing and oxidising improvers on free reduced and free oxidised glutathione and protein-glutathione mixed disulphides of wheat flour. European Food Research and Technology, 1996, 203(3): 255-261

97. Bick J A, Åslund F, Chen Y, Leustek T. Glutaredoxin function for the carboxyl-terminal domain of the plant-type 5'-adenylylsulfate reductase. Proceedings of the National Academy of Sciences of the United States of America, 1998, 95(14): 8404-8409
98. Frater R, Hird F J. The reaction of glutathione with serum albumin, gluten and flour proteins. Biochemical Journal, 1963, 88(1): 100105

99. Jones I K, Carnegie P R. Rheological activity of peptides, simple disulphides and simple thiols in wheaten dough. Journal of the Science of Food and Agriculture, 1969, 20(1): 60-64

100. Gupta R B, Khan K, Macritchie F. Biochemical basis of flour properties in bread wheats. I. Effects of variation in the quantity and size distribution of polymeric protein. Journal of Cereal Science, 1993, 18(1): 23-41

101. Zhang P, He Z, Zhang Y, Xia X, Chen D, Zhang Y. Association between \% SDS-unextractable polymeric protein (\%UPP) and enduse quality in Chinese bread wheat cultivars. Cereal Chemistry, 2008, 85(5): 696-700

102. Yu Z, Islam S, She M, Diepeveen D, Zhang Y, Tang G, Zhang J, Juhasz A, Yang R, Ma W. Wheat grain protein accumulation and polymerization mechanisms driven by nitrogen fertilization. Plant Journal, 2018, 96(6): 1160-1177

103. Carceller J, Aussenac T. Accumulation and changes in molecular size distribution of polymeric proteins in developing grains of hexaploid wheats: role of the desiccation phase. Functional Plant Biology, 1999, 26(4): 301-310

104. Gupta R B, Masci S, Lafiandra D, Bariana H S, MacRitchie F. Accumulation of protein subunits and their polymers in developing grains of hexaploid wheats. Journal of Experimental Botany, 1996, 47(9): $1377-1385$

105. Rhazi L, Cazalis R, Aussenac T. Sulfhydryl-disulfide changes in storage proteins of developing wheat grain: influence on the SDSunextractable glutenin polymer formation. Journal of Cereal Science, 2003, 38(1): 3-13 